\title{
Ventricular arrhythmias in Chagas disease
}

\author{
Marco Paulo Tomaz Barbosa ${ }^{[1],[2], ~ A n d r e ~ A s s i s ~ L o p e s ~ d o ~ C a r m o ~}{ }^{[1],[2],}$ \\ Manoel Otávio da Costa Rocha ${ }^{[1]}$ and Antonio Luiz Pinho Ribeiro ${ }^{[1],[2]}$
}

[1]. Departamento de Clínica Médica, Faculdade de Medicina, Universidade Federal de Minas Gerais, Belo Horizonte, MG. [2]. Serviço de Cardiologia e Cirurgia Cardiovascular, Hospital das Clínicas, Universidade Federal de Minas Gerais, Belo Horizonte, MG.

\begin{abstract}
Sudden death is one of the most characteristic phenomena of Chagas disease, and approximately one-third of infected patients develop life-threatening heart disease, including malignant ventricular arrhythmias. Fibrotic lesions secondary to chronic cardiomyopathy produce arrhythmogenic substrates that lead to the appearance and maintenance of ventricular arrhythmias. The objective of this study is to discuss the main clinical and epidemiological aspects of ventricular arrhythmias in Chagas disease, the specific workups and treatments for these abnormalities, and the breakthroughs needed to determine a more effective approach to these arrhythmias. A literature review was performed via a search of the PubMed database from 1965 to May 31, 2014 for studies of patients with Chagas disease. Clinical management of patients with chronic Chagas disease begins with proper clinical stratification and the identification of individuals at a higher risk of sudden cardiac death. Once a patient develops malignant ventricular arrhythmia, the therapeutic approach aims to prevent the recurrence of arrhythmias and sudden cardiac death by the use of implantable cardioverter defibrillators, antiarrhythmic drugs, or both. In select cases, invasive ablation of the reentrant circuit causing tachycardia may be useful. Ventricular arrhythmias are important manifestations of Chagas cardiomyopathy. This review highlights the absence of high-quality evidence regarding the treatment of ventricular arrhythmias in Chagas disease. Recognizing high-risk patients who require specific therapies, especially invasive procedures such as the implantation of cardioverter defibrillators and ablative approaches, is a major challenge in clinical practice.
\end{abstract}

Keywords: Chagas disease. Arrhythmia. Sudden death. Pacemaker. Implantable cardioverter.

\section{INTRODUCTION}

Chagas disease is a major medical and social problem in Latin America and affects 8-10 million people. It has substantial impacts on the economy and on morbidity and mortality ${ }^{(1),(2)}$. More recently, with increased migration, it has also become a problem for developed countries, which now have hundreds of thousands of patients with this disease ${ }^{3}$. The clinical course of the disease is extremely variable, and although many individuals remain asymptomatic for long periods, approximately one-third of infected patients develop life-threatening heart disease, including malignant ventricular arrhythmias ${ }^{(3),(4)}$.

Ventricular arrhythmias associated with Chagas heart disease $(\mathrm{ChD})$ have high rates of morbidity and mortality ${ }^{(3)}$. In this narrative literature review, we discuss the main clinical and epidemiological aspects of ventricular arrhythmias in $\mathrm{ChD}$, as well as specific workups and treatment. Finally, we discuss the breakthroughs needed to develop a more effective approach to these arrhythmias.

\footnotetext{
Address to: Dr. Antonio Luiz Pinho Ribeiro. Rua Campanha R no 98/101, Carmo, 30310-770 Belo Horizonte, MG, Brasil.

Phone: 5531 3409-9437

e-mail: tom@hc.ufmg.br

Received 10 January 2014

Accepted 17 November 2014
}

\section{METHODOLOGY}

A narrative review of the literature was performed. The PubMed database was searched for articles published from 1965 to May 31, 2014 to identify studies of patients with Chagas disease.

The PubMed search included the search filter in humans and the following keywords: [Chagas cardiomyopathy (MeSH) or Chagas disease $(\mathrm{MeSH})]$ and [Arrhythmias, cardiac $(\mathrm{MeSH})$ or Pacemakers (MeSH)] or Defibrillators, implantable (MeSH) or Amiodarone (MeSH Terms) or Death, sudden, cardiac (MeSH Terms) or Heart arrest (MeSH Terms) or Tachycardia, ventricular (MeSH Terms) or Ventricular fibrillation (MeSH Terms)]. We also used the related articles search strategy for each relevant article. An additional search was conducted of the Virtual Health Library (VHL) (http://www.bireme.br/ php/index.php) using the LILACS database with Boolean combinations of descriptors. Reference texts read in their entirety were used as further sources of articles. The results were ordered alphabetically by author to identify redundant studies that examined the same patients; institutions, dates, and study designs were also examined to identify redundancies.

\section{PATHOGENESIS AND PATHOPHYSIOLOGY}

The main arrhythmogenic substrates in $\mathrm{ChD}$ are necrotic and fibrotic lesions caused by inflammation of the myocardium ${ }^{(5)}$. The lesions are also associated with blood flow impairment secondary to microvascular lesions or autonomic changes 
that regulate blood perfusion of the injured myocardium ${ }^{(6)}$. The lesions caused by inflammatory processes damage the intercellular junctions that are associated with changes in electrical potential and compromise stimulus conduction between cells. These changes cause electrical uncoupling that results in the slow conduction of stimuli and unidirectional block. This process, coupled with the fibrotic areas, forms the reentrant circuit that causes ventricular arrhythmias ${ }^{(7),(8)}$. It is postulated that cardiac dysautonomia, a typical finding in Chagas disease, may be related to the pathogenesis of and risk associated with ventricular arrhythmias in $\mathrm{ChD}^{(9),(10)}$. In experimental models, denervation in the severe acute phase is followed by partial or total reinnervation, either through axonal sprouting from intact vagal neurons or by sympathetic terminations of axonal regrowth ${ }^{(11)}$. The coexistence of denervated and hyperinnervated areas in the diseased myocardium could result in increased electrophysiological heterogeneity during sympathetic activation and may lead to ventricular arrhythmia and sudden cardiac death ${ }^{(12)}$. Despite the well-established association between impaired autonomic cardiac modulation and sudden death in other clinical settings ${ }^{(13)}$, this association in $\mathrm{ChD}$ remains hypothetical. However, an association between sympathetic innervation defects (as detected by iodine-123 meta-iodobenzylguanidine scintigraphic studies) and sustained ventricular tachycardia (VT) has been demonstrated ${ }^{(14)}$, and autonomic-driven abnormal heart rate dynamics have been shown to precede ventricular tachycardia in $\mathrm{ChD}$ patients ${ }^{(14)}$.

\section{DETECTING SEVERITY AND PROGNOSIS}

\section{Resting electrocardiogram and signal-averaged ECG}

An electrocardiogram (ECG) is important for both the diagnosis and prognosis of $\mathrm{ChD}$, although the sensitivity of ECG for detecting myocardial injury is low. The absence of changes in an ECG is not a reliable indicator of the absence of cardiac involvement ${ }^{(15)}$, despite several cohort studies showing that patients with a normal ECG have an excellent prognosis after 5-10 years of follow-up and rarely develop severe global left ventricular dysfunction ${ }^{(2),(16),(17)}$. However, the onset of new electrocardiographic alterations can help to identify patients with substantially decreased ( $\geq 5 \%$ ) left ventricular ejection fraction (LVEF) ${ }^{(18)}$.

Atrioventricular and intraventricular conduction disorders are common manifestations of $\mathrm{ChD}$ and are usually related to ventricular systolic dysfunction and ventricular arrhythmias ${ }^{(19)}$. Right bundle branch block (RBBB) is the most common electrocardiographic abnormality observed in $\mathrm{ChD}$. It is typically associated with left anterior hemiblock and ventricular premature beats (VPBs). Left bundle branch block (LBBB) is less common and is associated with a worse prognosis ${ }^{(20)}$. RBBB is found in $13-35 \%$ of patients with heart disease. LBBB is ten times less common than $\mathrm{RBBB}^{(16),(21),(22)}$. The QRS duration is directly related to the left ventricular size and inversely related to the $\mathrm{LVEF}^{(22)}$. The duration of the filtered QRS, obtained by means of a signal-averaged ECG, is an independent predictor of death in $\mathrm{ChD}^{(23)}$.

\section{Dynamic ECG recording (Holter monitoring)}

Holter monitoring is important in the diagnosis and prognosis of $\mathrm{ChD}$. VPBs are common in $\mathrm{ChD}$ : approximately $15-55 \%$ of individuals with positive serology for Chagas present with VPBs ${ }^{(21)}$. VPBs can also be observed in approximately $10 \%$ of infected individuals with no evidence of structural heart disease ${ }^{(24)}$. The presence of numerous, polymorphic, and complex extrasystoles is associated with more severe heart disease ${ }^{(16)}$. The occurrence of VPBs with multiple morphologies is a relatively common finding that has been attributed to extensive myocardial damage and correlates with the presence of late potentials observed using signal-averaged ECG ${ }^{(25)}$.

When Chagas patients with abnormal ECGs at rest and during heart failure are studied by dynamic electrocardiography, virtually all of them (99\%) present with VPBs, and $87 \%$ have multiform VPBs or repetitive forms, such as non-sustained ventricular tachycardia (NSVT) ${ }^{26}$.

\section{Benign versus malignant arrhythmias}

The presence of NSVT during electrocardiographic monitoring is a prognostic factor for overall mortality and sudden cardiac death in patients with ventricular systolic dysfunction ${ }^{(21),(26-28)}$. Complex ventricular arrhythmias, such as frequent or polymorphic VPBs, pairs, NSVT and sustained VT, are often found in Chagas cardiomyopathy and translate into a high risk of sudden cardiac death ${ }^{(8),(29),(30)}$. In ChD patients with depressed ventricular function on echocardiography, complex ventricular arrhythmias are independent predictors of fatal outcomes $^{(23),(31)}$.

\section{Exercise test}

Chagas cardiomyopathy patients can safely take exercise stress tests. The test can detect exercise-induced arrhythmias and determine a patient's New York Heart Association functional class and the type and amount of work the patient can perform. The presence of VT during the exercise test is a predictor of sudden death in patients with Chagas cardiomyopathy and ventricular arrhythmias detected using Holter monitoring ${ }^{(32)}$. However, the clinical usefulness of the exercise test is questionable. The feasibility of selecting patients at risk of sudden death for a more aggressive treatment based on a VTinduced exercise test has not been assessed. Chronotropic incompetence and an abnormal blood-pressure response can impair the exercise capacity of patients with $\mathrm{ChD}^{(3),(34)}$.

\section{TREATMENT}

\section{Antiarrhythmic drugs}

Amiodarone is widely used as an antiarrhythmic agent in patients with ChD. Haedo et al. ${ }^{(35)}$ and Rosenbaum et al. ${ }^{(36)}$ showed that amiodarone is the most effective antiarrhythmic drug in Chagas cardiomyopathy and is well tolerated. Thyroid dysfunction and dermatological abnormalities are not uncommon, but severe pulmonary toxicity is rare. Because of its toxicity, amiodarone should not be used in patients with mild disease or a good prognosis. Simple and monomorphic VPBs have no impact on the prognosis of $\mathrm{ChD}$ and do not 
require specific treatment. Patients with complex ventricular extrasystoles or NSVT with no symptoms or significant ventricular dysfunction also do not require antiarrhythmic therapy. There are, however, controversies surrounding the use of antiarrhythmic therapy in complex ventricular ectopy in patients with reduced LVEF. Studies of patients with dilated cardiomyopathies due to causes other than $\mathrm{ChD}$ found no reduction in mortality with the use of amiodarone. A metaanalysis of all of the randomized trials that have assessed the use of amiodarone versus a placebo for the prevention of sudden death has recently been published ${ }^{(37)}$. Amiodarone was shown to decrease the incidence of sudden death [7.1 vs. 9.7\%, odds ratio (OR) 0.71 (0.61-0.84), $\mathrm{p}=0.01]$ and cardiovascular death [14.0 vs. $16.3 \%$, OR (0.71-0.94), $p=0.004]$, but it failed to alter mortality due to all causes and was associated with a fivefold increase in the risk of thyroid and pulmonary toxicity. These findings did not differ between patients with ischemic cardiomyopathy and those with non-ischemic cardiomyopathy.

Although this meta-analysis included only a small number of patients with $\mathrm{ChD}$, amiodarone represents a viable alternative for patients with ventricular systolic dysfunction and ventricular arrhythmia who are not eligible for, or do not have access to, an implantable cardioverter defibrillator (ICD).

Frequent use of antiarrhythmic drugs is also important in the attempt to reduce the numbers of shocks triggered by implanted defibrillators. There is evidence that the use of antiarrhythmic drugs may decrease the number of shocks ${ }^{(30),(38),(39)}$. In other cardiomyopathies, the combined use of amiodarone and beta-blockers reduced the number of therapies that were needed ${ }^{(30),(38),(39)}$. Decreasing the number of shocks triggered by the defibrillator is an important treatment goal for a variety of reasons. A high burden of shocks can contribute to mortality by causing myocardial necrosis and promoting or exacerbating ventricular dysfunction ${ }^{(40),(41)}$.

\section{Antiarrhythmic drugs and left ventricular dysfunction}

The most frequent ventricular arrhythmias in patients with Chagas disease are ventricular, isolated and repetitive ectopic beats. Antiarrhythmic treatment is not required in asymptomatic patients with preserved ventricular function. In symptomatic patients without ventricular dysfunction, antiarrhythmic treatment can be individualized. When ventricular ectopy and NSVT are present in patients with left ventricular dysfunction, amiodarone is a safe drug to use. Despite an absence of evidence that amiodarone changes the prognosis of these patients, its effects on the long-term reduction in the power density of the arrhythmias and on the control of symptoms is well known.

\section{Electrophysiologically guided therapy}

Electrophysiologically (EP) guided antiarrhythmic drug therapy has been evaluated in patients with $\mathrm{ChD}$ and with other cardiomyopathies, based on the hypothesis that the noninducibility of VT with antiarrhythmic drug use can predict low rates of the recurrence of arrhythmia and, in some cases, preclude ICD implantation. This strategy was evaluated in the the multicenter unsustained tachycardia trial ${ }^{(42)}$ in patients with ischemic cardiomyopathy and sustained VT-inducible EP; the study found that the benefits of ICD implantation exceed those of EP-guided therapy and that patients with implanted ICDs fared better than control patients.

According to these studies, which primarily evaluated patients with ischemic heart disease, best practices should include ICD implantation, irrespective of the therapy adopted to prevent the recurrence of VT or ventricular fibrillation (VF). Nevertheless, prevention (or reduction of VT burden) is very important in the management of patients with structural heart disease and in particular in chagasic patients, who experience a high frequency of VT/VF recurrence. Leite et al. evaluated the efficacy of antiarrhythmic drug therapy (amiodarone or sotalol) in patients with Chagas cardiomyopathy and observed decreased survival in patients in whom unstable and inducible VT persisted after drug therapy ${ }^{(43)}$. Note that in this study, ICD implantation was not evaluated; therefore, it is not possible to draw conclusions regarding the indications for its use. Therefore, EP-guided strategies are restricted to patients unable to undergo ICD implantation or catheter ablation, which is described below.

\section{Implantable cardioverter defibrillator}

Episodes of malignant ventricular arrhythmias are more frequent in patients with $\mathrm{ChD}$ than in patients with other heart diseases $^{(44)}$.

The mechanisms most frequently involved in sudden death in $\mathrm{ChD}$ are malignant ventricular arrhythmia, VT degenerating into VF and VF not preceded by $\mathrm{VT}^{(8)}$.

The ICD allows early treatment of life-threatening tachyarrhythmias, and this early treatment has become the main therapeutic strategy for preventing sudden death in patients after myocardial infarction and in patients with dilated cardiomyopathy. The efficacy and safety of treatment with ICDs among patients with $\mathrm{ChD}$ has been evaluated in previous observational studies; however, no large randomized controlled trial has examined the efficacy and safety of treatment with ICDs in $\mathrm{ChD}$. Thus, the treatment of ventricular arrhythmias in chagasic patients using ICD implantation is essentially empirical, based on extrapolated recommendations for heart disease of other etiologies.

The American College of Cardiology (ACC), American Heart Association (AHA) and Heart Rhythm Society (HRS) 2008 Guidelines for Device-Based Therapy of Cardiac Rhythm Abnormalities recommended ICD implantation in ChD patients for primary and secondary prevention of sudden cardiac death ${ }^{(45)}$. The guidelines for ICD implantation defined by the Brazilian Ministry of Health ${ }^{(46)}$ recommend that ICDs be implanted in the following situations: I) Resuscitation from cardiac arrest due to documented sustained VT or VF due to a non-reversible cause, with LVEF less than or equal to $35 \%$ or structural heart disease; II) Spontaneous VT due to a non-reversible cause, with LVEF less than or equal to $35 \%$ or the presence of structural heart disease; III) Syncope of unknown origin, with inducible, hemodynamically unstable or clinically relevant VT or VF, with LVEF less than or equal to $35 \%$ or the presence of structural heart disease. 
A few prospective, observational studies and prospective, non-randomized studies have examined a limited number of Chagas disease patients. Studies of ICD implantation in patients with $\mathrm{ChD}$ have aimed to evaluate its efficacy and safety and to identify predictors of appropriate therapy ${ }^{(47),(48)}$. In addition, several studies have compared the results of ICD implantation in ChD patients with the results of ICD implantation in the non-chagasic population to identify similarities and differences between these populations ${ }^{(44),(49-52)}$. All of these studies investigated patients for whom ICD was indicated for the prevention of arrhythmias secondary to $\mathrm{ChD}$. Studies by Muratore et al. ${ }^{(50),(51)}$ and Fonseca et al ${ }^{(53)}$ found no difference between the populations with and without Chagas disease in the numbers of arrhythmia episodes, shocks, and deaths. In contrast, the studies by Martinelli-Filho et al. ${ }^{(44)}$, Rabinovich et al. ${ }^{(51)}$, Moreira ${ }^{(49)}$, Cardinalli-Neto et al. ${ }^{(54)}$, Cardinalli-Neto et al. ${ }^{(55)}$, Barbosa et al. ${ }^{(52)}$ and the ICD registry for patients with Chagas disease in Latin America, published in $2009^{(56)}$, found differences between the chagasic and non-chagasic populations. $\mathrm{ChD}$ groups had higher numbers of ventricular arrhythmias, a higher percentage of patients receiving appropriate therapy and increased numbers of shocks overall. The groups did not differ in the outcomes for mortality and the number of inappropriate shocks. Mortality predictors for Chagas disease patients with ICDs were the following: the number of shocks per patient ${ }^{(56)}$, age $\geq 65$ years $^{57}$ and LVEF $\leq 30 \%{ }^{(57)}$. Martinelli et al. ${ }^{(58)}$ investigated 116 consecutive $\mathrm{ChD}$ patients with ICDs implanted for the secondary prevention of arrhythmias; $50 \%$ of the cohort received appropriate shock therapy. A class III New York Heart Association score and LVEF were independent predictors of worse prognosis, while low cumulative right ventricular pacing was associated with better survival.

The use of ICDs appears to provide effective protection for Chagas patients and constitutes a safe procedure with low frequencies of inappropriate therapy and complications, despite having been assessed in only a few prospective and retrospective observational studies that examined limited numbers of patients. A recent study by Gali et al. ${ }^{(59)}$ compared the outcomes of $\mathrm{ChD}$ patients with life-threatening ventricular arrhythmias who were treated either with ICD implantation plus amiodarone or with amiodarone alone. Therapy with ICD plus amiodarone resulted in a $72 \%$ reduced risk of all-cause mortality $(p=0.007)$ and a $95 \%$ reduced risk of sudden death $(\mathrm{p}=0.006)$ compared with amiodarone-only therapy. The survival benefit associated with ICD was greatest in patients with LVEF $<40 \%(\mathrm{p}=0.01)$ and was not significant in those with LVEF $\geq 40 \%$ ( $p=0.15$ ). Appropriate ICD therapies occurred in $72 \%$ of patients, and the rates of interventions were similar across patients with LVEF $<$ $40 \%$ and those with LVEF $\geq 40 \%$. The majority of ICD-treated patients received appropriate therapies regardless of LV systolic function. Four findings of the present study are of particular importance. First, ICD therapy plus amiodarone was superior in reducing all-cause mortality in $\mathrm{ChD}$ patients with sustained ventricular arrhythmias compared with amiodarone therapy alone. Second, the benefits of ICD therapy resulted from a significant decrease in the risk of sudden death. Third, patients with $\mathrm{LVEF}<40 \%$ derived the most survival benefit from ICD.
Finally, ChD patients presenting with sustained ventricular arrhythmias are at high risk for the recurrence of arrhythmias, irrespective of the LV systolic function.

No information on the effectiveness of ICD implantation for primary prevention in Chagas patients without malignant ventricular arrhythmia is available, and no additional criteria, such as the presence of moderate or severe systolic ventricular dysfunction, have been examined.

A clinical trial addressing this issue has been designed ${ }^{(60)}$. The ACC/AHA/HRS 2008 Guidelines for Device-Based Therapy of Cardiac Rhythm Abnormalities recommends the implantation of ICD for primary prevention based solely on the presence of $\mathrm{ChD}^{45}$. Although beneficial to some patients, this policy would subject all patients to the risk of inappropriate shock, pro-arrhythmia, and perioperative and postoperative complications.

ICD implantation should be indicated only when it is costeffective and should be restricted to patients who can benefit from the treatment. Although high cost and clinical uncertainties limit the routine use of ICD in the primary prevention of sudden cardiac death in most Latin American countries, current evidence supports its use in secondary prevention in patients with Chagas disease.

\section{Ablation therapy}

In recent decades, ICD implantation has become the main therapy for sustained VT in patients with structural heart disease. ICDs treat VTs by delivering shocks or by providing antitachycardia pacing, effectively preventing arrhythmic sudden death. Nevertheless, the ICD-delivered shocks are painful and can substantially decrease the quality of life ${ }^{(40),(61)}$, a characteristic that calls attention to the importance of therapies that prevent VT recurrence. Because of the toxicity of antiarrhythmic drugs and their failure in preventing recurrences, ablation (surgical or catheter-based) is, for many patients, the only option to treat recurrent VT. Moreover, VT recurrence prevention decreases the burden of ICD therapy delivered and can improve the quality of life. One study revealed that ablation of all morphologies of VT induced by ventricular stimulation decreased heart failureinduced mortality ${ }^{(62)}$.

The electrophysiological mechanism of VT in Chagas disease is reentry ${ }^{(63)}$, and the main goal of ablation is to identify critical isthmuses that maintain tachycardia and to destroy small portions of the myocardium, thereby preventing the electrical impulses that perpetuate arrhythmias (Figure 1).

The most common site of origin of VT in Chagas cardiomyopathy is the left ventricle basal inferolateral wall ${ }^{(64),(65)}$ For patients with large areas of fibrosis, several morphologies of sustained VT can be induced, which require extensive mapping and ablation. In approximately $30 \%$ of sustained VT episodes, the reentrant circuits are also located on the epicardial surface. A non-surgical treatment approach became possible after the initial description by Sosa et al. of the percutaneous subxiphoid $\operatorname{access}^{(66)}$.

In patients with unstable VT, the traditional mapping system, during tachycardia, may be impossible due to severe hemodynamic compromise. Nevertheless, electroanatomical 


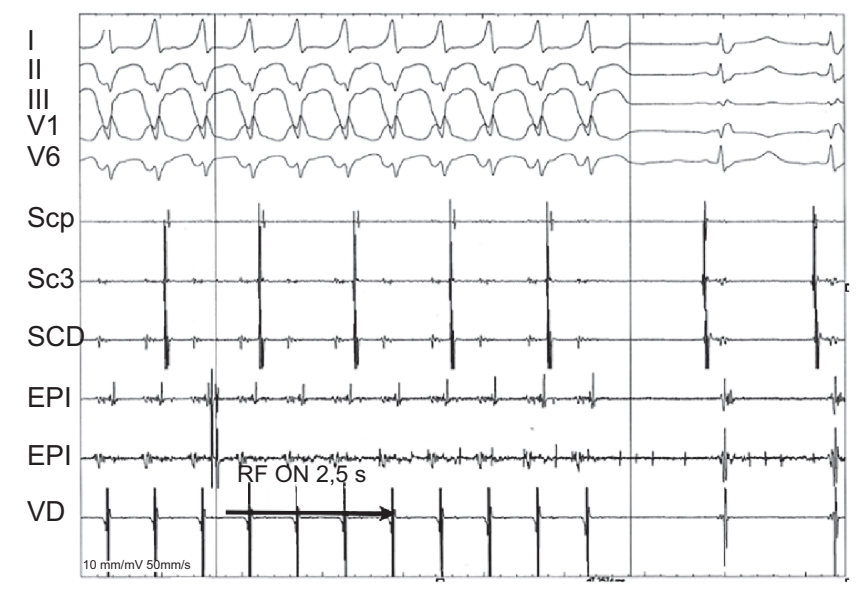

FIGURE 1 - Epicardial ablation of ventricular tachycardia, with arrhythmia interruption $2.5 \mathrm{~s}$ after radiofrequency stimulation was initiated.

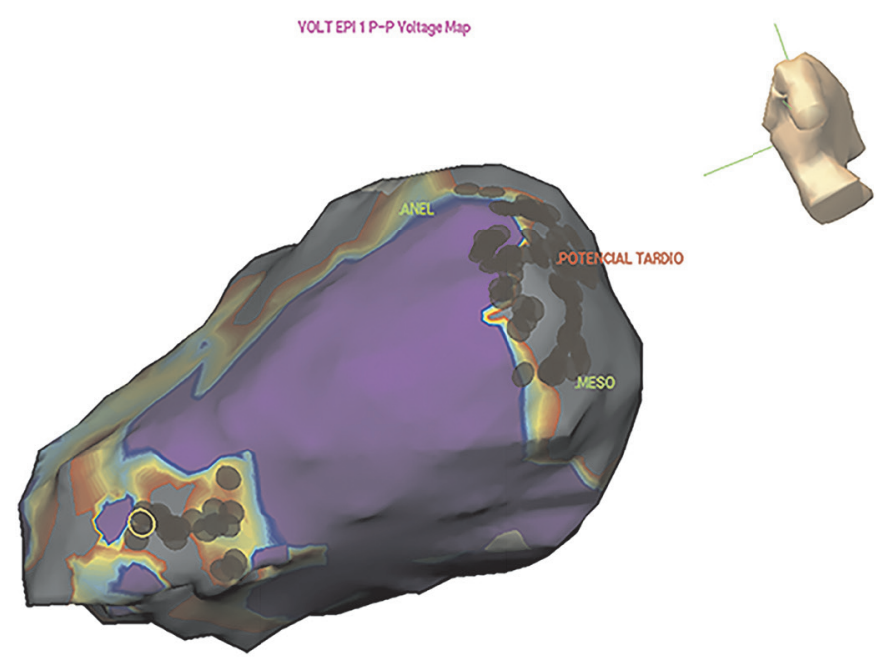

FIGURE 2 - Epicardial electroanatomical mapping of a patient with Chagas cardiomyopathy, identifying extensive scarring in the basolateral and apical walls of the left ventricle (gray area). The use of radiofrequency interrupted the VT (red dots). VT: ventricular tachycardia.

mapping (Figure 2) enables a detailed map of the scar in sinus rhythm, allowing substrate modification, even in patients with unstable arrhythmias.

Ablation is recommended for patients with VT secondary to structural heart disease in the following situations ${ }^{(67)}$ : I) For the control of symptomatic, sustained monomorphic VT, including VT terminated by ICD, which recurs despite antiarrhythmic drug therapy or when antiarrhythmic drugs are not tolerated or desirable; II) For the control of incessant, sustained monomorphic VT or a VT storm that is not due to a transient reversible cause; III) For the control of bundle branch reentrant or interfascicular VTs; IV) For the control of recurrent, sustained polymorphic VT or VF that is refractory to antiarrhythmic therapy and when there is a suspected trigger that can be targeted for ablation.

\section{CONCLUSIONS}

Ventricular arrhythmias are important manifestations of Chagas cardiomyopathy and are associated with increased disease severity and a high risk of death. Recognizing high-risk patients who require specific therapies and invasive procedures, such as ICD implantation and ablative approaches, is a major challenge in clinical practice.

\section{FUTURE PROPOSITIONS}

The development of a strategy to accurately predict which patients are at a high risk of presenting with malignant cardiac arrhythmia would allow effective preventive actions and a more rational use of available funds for the treatment of Chagas cardiomyopathy. Studies are also urgently needed to provide a comparison of the two treatment modalities (amiodarone versus ICD) in the primary prevention of total mortality and sudden death in $\mathrm{ChD}$ patients with low left ventricular ejection fraction.

\section{CONFLICT OF INTEREST}

The authors declare that there is no conflict of interest.

\section{FINANCIAL SUPPORT}

Manoel Otávio da Costa Rocha and Antônio Luiz Pinho Ribeiro are recipients of research scholarships from CNPq (Conselho Nacional de Desenvolvimento Cientifico e Tecnológico) e FAPEMIG [Fundação de Amparo à Pesquisa de Minas Gerais (Programa Pesquisador Mineiro)].

\section{REFERENCES}

1. Bardy GH, Lee KL, Mark DB, Poole JE, Packer DL, Boineau R, et al. Amiodarone or an implantable cardioverter, defibrillator for congestive heart failure. N Engl J Med 2005; 352:225-237.

2. Ribeiro AL, Rocha MO. Forma indeterminada da doença de Chagas: considerações acerca do diagnóstico e do prognóstico. Rev Soc Bras Med Trop 1998; 31:301-314.

3. Ribeiro AL, Nunes MP, Teixeira MM, Rocha MO. Diagnosis and management of Chagas disease and cardiomyopathy. Nat Rev Cardiol 2012; 9:576-589.

4. Ribeiro RA, Stella SF, Zimerman LI, Pimentel M, Rohde LE, Polanczyk CA. Custo-efetividade de cardiodesfibriladores implantáveis no Brasil nos setores público e privado. Arq Bras Cardiol 2010; 95 : 577-586.

5. Milei J, Pesce R, Valero E, Muratore C, Beigelman R, Ferrans VJ. Electrophysiologic-structural correlations in chagasic aneurysms causing malignant arrhythmias. Int J Cardiol 1991; 32:65-73.

6. Rossi MA, Tanowitz HB, Malvestio LM, Celes MR, Campos EC, Blefari V, et al. Coronary microvascular disease in chronic Chagas cardiomyopathy including an overview on history, pathology, and other proposed pathogenic mechanisms. PLoS Negl Trop Dis 2010; 4:674. 
7. Feldman AM, McNamara D. Myocarditis. N Engl J Med 2000; 343:1388-1398.

8. Carvalho AC, TLanowitz HB, Wittner M, Dermietzel R, Roy C, Hertzberg E, et al. Gap junction distribution is altered between cardiac myocytes infected with Trypanosoma cruzi. Circ Res 1992; 70:733-742.

9. Junqueira Jr LF. Insights into the clinical and functional significance of cardiac autonomic dysfunction in Chagas disease. Rev Soc Bras Med Trop 2012; 45:243-252.

10. Machado CR, Gomez MV, Machado AB. Changes in choline acetyltransferase activity of rat tissues during Chagas' disease. Braz J Med Biol Res 1987; 20:697-702.

11. Machado CR, Machado AB, Chiari CA. Recovery from heart norepinephrine depletion in experimental Chagas' disease. Am J Trop Med Hyg 1978; 27:20-24.

12. Chen LS, Zhou S, Fishbein MC, Chen PS. New perspectives on the role of autonomic nervous system in the genesis of arrhythmias. J Cardiovasc Electrophysiol 2007; 18:123-127.

13. La Rovere MT, Pinna GD, Maestri R, Mortara A, Capomolla S, Febo O, et al. Short-term heart rate variability strongly predicts sudden cardiac death in chronic heart failure patients. Circulation 2003; 107:565-570.

14. Miranda CH, Figueiredo AB, Maciel BC, Marin-Neto JA, Simões MV. Sustained Ventricular Tachycardia Is Associated with Regional Myocardial Sympathetic Denervation Assessed with 123I-Metaiodobenzylguanidine in Chronic Chagas Cardiomyopathy. J Nucl Cardiol 2011; 52:504-510.

15. Dias E, Laranja FS, Nobrega G. Doença de Chagas. Mem Inst Oswaldo Cruz 1945; 42:530-545.

16. Maguire JH, Hoff R, Sherlock I, Guimarães AC, Sleigh AC, Ramos NB, et al. Cardiac morbidity and mortality due to Chagas' disease: prospective electrocardiographic study of a Brazilian community, Circulation 1987; 75:1140-1145.

17. Dias JC. The indeterminate form of human chronic Chagas' disease: a clinical epidemiological review. Rev Soc Bras Med Trop 1989; 22:147-156.

18. Nascimento BR. The prognostic significance of electrocardiographic changes in Chagas disease. J Electrocardiol 2012; 45:43-48.

19. Chagas C, Villela E. Cardiac form of American Trypanosomiasis. Mem Inst Oswaldo Cruz 2012; 14:5-91.

20. Dias JC, Kloetzel K. The prognostic value of the electrocardiographic features of chronic Chagas' disease. Rev Inst Med Trop Sao Paulo 1968; 10:158-162.

21. Garzon SA, Lorga AM, Nicolau JC. Electrocardiography in Chagas' heart disease, Sao Paulo Med J 1995; 113:802-813.

22. Ribeiro AL, Rocha MO, Barros MV, Rodrigues AR, Machado FS. A narrow QRS does not predict a normal left ventricular function in Chagas' disease. Pacing Clin Electrophysiol 2000; 23:2014-2017.

23. Ribeiro AL, Cavalvanti PS, Lombardi F, Nunes Mdo C, Barros MV, Rocha MO. Prognostic value of signal-averaged electrocardiogram in Chagas disease, J Cardiovasc Electrophysiol 2008; 19:502-509.

24. Elizari M. Arrhythmias Associated with Chagas' Disease. Cardiac Electrophysiology Review 1997; 1:270-273.

25. Muratore CA, Baranchuk A. Current and emerging therapeutic options for the treatment of chronic chagasic cardiomyopathy. Vasc Health Risk Manag 2010; 6:593-601.

26. Carrasco HA, Guerrero L, Parada H, Molina C, Vegas E, Chuecos R. Ventricular arrhythmias and left ventricular myocardial function in chronic chagasic patients. Int J Cardiol 1990; 28:35-41.

27. de Sousa MR, Morillo CA, Rabelo FT, Nogueira Filho AM, Ribeiro AL. Non-sustained ventricular tachycardia as a predictor of sudden cardiac death in patients with left ventricular dysfunction: A meta-analysis. Eur J Heart Fail 2008; 10:1007-1014.
28. Marin Neto JA, Simões MV, Sarabanda AV. Chagas' heart disease. Arq Bras Cardiol 1999; 72:247-280.

29. Rocha MO, Ribeiro AL, Teixeira MM. Clinical management of chronic Chagas cardiomyopathy. Front Biosci 2003; 8:44-54.

30. Rassi Jr A, Rassi A, Little WC, Xavier SS, Rassi SG, Rassi AG, et al. Development and validation of a risk score for predicting death in Chagas' heart disease. N Engl J Med 2006; 355:799-808.

31. Guerrero L, Carrasco H, Parada H, Molina C, Chuecos R. Ventricular mechanics and cardiac arrhythmias in patients with chagasic and primary dilated cardiomyopathy. Echo-electrocardiographic follow-up. Arq Bras Cardiol 1991; 56:465-469.

32. de Paola AA, Gomes JA, Terzian AB, Miyamoto MH, Martinez Fo EE. Ventricular tachycardia during exercise testing as a predictor of sudden death in patients with chronic chagasic cardiomyopathy and ventricular arrhythmias. Br Heart J 1995; 74:293-295.

33. Rocha AL. Chronotropic incompetence and abnormal autonomic modulation in ambulatory Chagas disease patients. Ann Noninvasive Electrocardiol 2006; 11:3-11.

34. Rocha AL. Índice cronotrópico-metabólico na doença de Chagas. Rev Soc Bras Med Trop 2005; 38:373-376.

35. Haedo AH, Chiale PA, Bandieri JD, Lázzari JO, Elizari MV, Rosenbaum MB. Comparative antiarrhythmic efficacy of verapamil, 17-monochloracetylajmaline, mexiletine and amiodarone in patients with severe chagasic myocarditis: relation with the underlying arrhythmogenic mechanisms. J Am Coll Cardiol 1986; 7:1114-1120.

36. Rosenbaum M, Posse R, Sgammini H, Núñez Burgos J, Chiale PA, Pastori JD, et al. Comparative multicenter clinical study of flecainide and amiodarone in the treatment of ventricular arrhythmias associated with chronic Chagas cardiopathy. Arch Inst Cardiol Mex 1987; 57:325-330.

37. Piccini JP, Berger JS, O'Connor CM. Amiodarone for the prevention of sudden cardiac death: a meta-analysis of randomized controlled trials. Eur Heart J 2009; 30:1245-1253.

38. Satomi K, Kurita T, Takatsuki S, Yokoyama Y, Chinushi M, Tsuboi $\mathrm{N}$, et al. Amiodarone therapy in patients implanted with cardioverterdefibrillator for life-threatening ventricular arrhythmias. Circulation 2006; 70:977-984.

39. Rassi Júnior A, Gabriel Rassi A, Gabriel Rassi S, Rassi Júnior L, Rassi A. Ventricular arrhythmia in Chagas disease. Diagnostic, prognostic, and therapeutic features. Arq Bras Cardiol 1995; 65:377387.

40. Connolly SJ, Dorian P, Roberts RS, Gent M, Bailin S, Fain ES, et al. Comparison of $\{$ beta $\}$-blockers, amiodarone plus \{beta\}-blockers, or sotalol for prevention of shocks from implantable cardioverter defibrillators: The OPTIC study: A randomized Trial. JAMA 2006; 295:165-171.

41. Poole JE, Johnson GW, Hellkamp AS, Anderson J, Callans DJ, Raitt $\mathrm{MH}$, et al. prognostic importance of defibrillator shocks in patients with heart failure, N Engl J Med 2008; 359:1009-1017.

42. Buxton AE, Lee KL, Fisher JD, Josephson ME, Prystowsky EN, Hafley G. A randomized study of the prevention of sudden death in patients with coronary artery disease. N Engl J Med 1999; 341: 1882-1890.

43. Leite LR, Fenelon G, Simoes A Jr, Silva GG, Friedman PA, de Paola AA. Clinical usefulness of electrophysiologic testing in patients with ventricular tachycardia and chronic chagasic cardiomyopathy treated with amiodarone or sotalol. J Cardiovasc Electrophysiol 2003; 14:567-573.

44. Martinelli Filho M, De Siqueira SF, Moreira H, Fagundes A, Pedrosa A, Nishioka SD, et al. Probability of occurrence of lifethreatening ventricular arrhythmias in Chagas' disease versus nonChagas' disease. Pacing Clin Electrophysiol 2000; 23:1944-1946. 
45. Epstein AE, Di Marco JP, Ellenbogen KA, Estes NA $3^{\text {rd }}$, Freedman RA, Gettes LS, et al. ACC/AHA/HRS 2008 Guidelines for DeviceBased Therapy of Cardiac Rhythm Abnormalities: A Report of the American College of Cardiology/American Heart Association Task Force on Practice Guidelines (Writing Committee to Revise the ACC/AHA/NASPE 2002 Guideline Update for Implantation of Cardiac Pacemakers and Antiarrhythmia Devices): Developed in Collaboration With the American Association for Thoracic Surgery and Society of Thoracic Surgeons. Circulation 2008; 117:350-408.

46. Ministério da Saúde. Secretaria de Atenção à Saúde. Portaria 152 de 08 de março de 2007. Diário Oficial 8-3-2007. Brasília: Ministério da Saúde; 2007.

47. Cardinalli-Neto A, Greco OT, Bestetti RB. Automatic implantable cardioverter-defibrillators in Chagas' heart disease patients with malignant ventricular arrhythmias. Pacing Clin Electrophysiol 2006; 29:467-470.

48. Cardinalli-Neto A, Bestetti RB, Cordeiro JA, Rodrigues VC. Predictors of all-cause mortality for patients with chronic Chagas' heart disease receiving implantable cardioverter defibrillator therapy. J Cardiovasc Electrophysiol 2007; 18:1236-1240.

49. Moreira HB. Probabilidade de ocorrência de morte súbita cardíaca na cardiomiopatia chagásica e não chagásica. Reblampa 2003; 16:55-58.

50. Muratore C, Rabinovich R, Iglesias R, González M, Darú V, Liprandi AS. Implantable cardioverter defibrillators in patients with Chagas' disease: are they different from patients with coronary disease? Pacing Clin Electrophysiol 1997; 20:194-197.

51. Rabinovich R, Muratore C, Iglesias R, Gonzalez M, Darú V, Valentino M, et al. Time to first shock in implantable cardioverter defibrillator (ICD) patients with Chagas cardiomyopathy. Pacing Clin Electrophysiol 1999; 22:202-205.

52. Barbosa MP, da Costa Rocha MO, de Oliveira AB, Lombardi F, Ribeiro AL. Efficacy and safety of implantable cardioverterdefibrillators in patients with Chagas disease, Europace 2013; 15:957-962.

53. da Fonseca SM, Belo LG, Carvalho H, Araújo N, Munhoz C, Siqueira L, et al. Clinical follow-up of patients with implantable cardioverter-defibrillator. Arq Bras Cardiol 2007; 88:8-16.

54. Cardinalli-Neto A, Greco OT, Bestetti RB. Automatic implantable cardioverter-defibrillators in Chagas' heart disease patients with malignant ventricular arrhythmias. Pacing Clin Electrophysiol 2006; 29:467-470.

55. Cardinalli-Neto A, Bestetti RB, Cordeiro JA, Rodrigues VC. Predictors of all-cause mortality for patients with chronic Chagas' heart disease receiving implantable cardioverter defibrillator Therapy. J Cardiovasc Electrophysiol 2007; 18:1236-1240.

56. Muratore CA, Batista Sa LA, Chiale PA, Eloy R, Tentori MC, Escudero J, et al. Implantable cardioverter defibrillators and Chagas' disease: results of the ICD Registry Latin America. Europace 2009; 11:164-168.
57. di Toro D, Muratore C, Aguinaga L, Batista L, Malan A, Greco $\mathrm{O}$, et al. Predictors of All-cause 1-year mortality in implantable cardioverter defibrillator patients with chronic Chagas' Cardiomyopathy. Pacing Clin Electrophysiol 2011; 34:1063-1069.

58. Martinelli M, de Siqueira SF, Sternick EB, Rassi Jr A, Costa R, Ramires JA, et al. Long-Term Follow-Up of Implantable Cardioverter-Defibrillator for Secondary Prevention in Chagas' Heart Disease. Am J Cardiol 2012; 110:1040-1045.

59. Gali WL, Sarabanda AV, Baggio JM, Ferreira LG, Gomes GG, Marin-Neto JA, et al. Implantable cardioverter-defibrillators for treatment of sustained ventricular arrhythmias in patients with Chagas' heart disease: comparison with a control group treated with amiodarone alone. Europace 2014; 6: 674-680.

60. Martinelli M, Rassi Jr A, Marin-Neto JA, de Paola AA, Berwanger O, Scanavacca MI, et al. Chronic use of amiodarone against implantable cardioverter-defibrillator therapy for primary prevention of death in patients with Chagas cardiomyopathy Study: Rationale and design of a randomized clinical trial. Am Heart J 2013; 166:976-982.

61. Schron EB, Exner DV, Yao Q, Jenkins LS, Steinberg JS, Cook JR, et al. Quality of Life in the Antiarrhythmics Versus Implantable Defibrillators Trial: Impact of Therapy and Influence of Adverse Symptoms and Defibrillator Shocks. Circulation 2002; 105:589-594.

62. Della Bella P, De Ponti R, Uriarte JA, Tondo C, Klersy C, Carbucicchio $\mathrm{C}$, et al. Catheter ablation and antiarrhythmic drugs for haemodynamically tolerated post-infarction ventricular tachycardia. Long-term outcome in relation to acute electrophysiological findings. Eur Heart J 2002; 23:414-424.

63. de Paola AA, Horowitz LN, Miyamoto MH, Pinheiro R, Ferreira DF, Terzian AB, et al. Angiographic and electrophysiologic substrates of ventricular tachycardia in chronic Chagasic myocarditis. Am J Cardiol 1990; 65:360-363.

64. Sosa E, Scanavacca M, D'Avila A, Bellotti G, Pilleggi F. Radiofrequency catheter ablation of ventricular tachycardia guided by nonsurgical epicardial mapping in chronic Chagasic heart disease. Pacing Clin Electrophysiol 1999; 22:128-130.

65. Sarabanda AV, Sosa E, Simões MV, Figueiredo GL, Pintya AO, MarinNeto JA. Ventricular tachycardia in Chagas' disease: a comparison of clinical, angiographic, electrophysiologic and myocardial perfusion disturbances between patients presenting with either sustained or nonsustained forms. Int J Cardiol 2005; 102:9-19.

66. Sosa E, Scanavacca M, d'Avila A, Pilleggi F. A new technique to perform epicardial mapping in the electrophysiology laboratory, J Cardiovasc Electrophysiol 1996; 7:531-536.

67. Aliot EM, Stevenson WG, Almendral-Garrote JM, Bogun F, Calkins CH, Delacretaz E, et al. EHRA/HRS Expert Consensus on catheter ablation of ventricular arrhythmias: Developed in a partnership with the European Heart Rhythm Association (EHRA), a Registered Branch of the European Society of Cardiology (ESC), and the Heart Rhythm Society (HRS); in collaboration with the American College of Cardiology (ACC) and the American Heart Association (AHA). Heart Rhythm 2009; 6:886-933. 